No. 20-14

\title{
Larceny in the Product Market: A Hidden Tax?
}

\author{
Osborne Jackson and Thu Tran
}

\begin{abstract}
:
This paper compares the distortionary impact of larceny theft across different product markets, characterizing such crime as a "hidden tax" on producers or consumers. We estimate the size of this tax and how it is affected by exogenous changes in larceny rates driven by the enactment of higher felony larceny thresholds. Pre-enactment hidden tax rates are small, ranging from 0.1 percent to 0.4 percent. These tax rates rise or fall with enactment, varying by product market. Such exogenous changes in the hidden tax induce state-level annual welfare changes that are minimal, ranging from $-\$ 1,500$ to $\$ 4,700$ across product markets.
\end{abstract}

JEL Classifications: K14, H20, D60

Keywords: larceny thresholds, crime, product markets, taxation, welfare

Osborne Jackson is a senior economist in the research department of the Federal Reserve Bank of Boston. His email is osborne.jackson@bos.frb.org. Thu Tran is a senior research assistant in the Boston Fed's research department. Her email is thu.tran@bos.frb.org.

The authors thank Aaron Cobet at the Bureau of Labor Statistics for his valuable advice regarding the Consumer Expenditure Survey. They also appreciate the helpful feedback from Jeff Thompson, as well as the beneficial edits from Lawrence Bean. Outstanding research assistance was provided by Katie Cox.

This paper presents preliminary analysis and results intended to stimulate discussion and critical comment.

The views expressed herein are those of the authors and do not indicate concurrence by the Federal Reserve Bank of Boston, the principals of the Board of Governors, or the Federal Reserve System. All errors are the authors' own.

This paper, which may be revised, is available on the website of the Federal Reserve Bank of Boston at https://www.bostonfed.org/publications/research-department-working-paper.aspx. 


\section{Introduction}

Larceny theft accounts for a striking 11 percent of felony convictions in the United Statesthe highest such percentage for any type of theft crime (Rosenmerkel, Durose, and Farole Jr. 2009). Given such prevalence, larceny crime has the scope to have large implications for social welfare. However, quantifying the societal impact of larceny crime depends on how one theorizes the welfare implications of such theft. Some observers have used the term "hidden tax" to describe the social consequences of larceny crime, hypothesizing that some of the costs borne by producers who face such theft are passed on to consumers in the form of higher prices paid. ${ }^{1}$ Similarly, costs borne by consumers who face larceny theft could be passed along to producers in the form of lower prices received. However, while there is an extensive literature on the welfare costs of standard taxation (as discussed by Auerbach 1985, for instance), no work, to our knowledge, formally examines larceny crime as a "tax" and calculates the welfare costs of such crime in that context. ${ }^{2}$

Our study therefore analyzes larceny crime as a hidden tax in order to examine its welfare implications. Using traditional tax theory, we first characterize how larceny crime might create distortions in a given product market. Then, extending empirical work by Jackson (2020) that relies on difference-in-differences comparisons of larceny and non-larceny theft, we use the enactment of higher felony larceny thresholds to generate exogenous variation in larceny crime by product market. These larceny thresholds reflect state-specific legislation that determines the dollar value of stolen property at or above which a larceny offense may be charged in court as a felony rather than a misdemeanor. We calculate baseline hidden tax rates and then examine how the aforementioned policy-driven exogenous changes in larceny crime affect this tax. Lastly, given these estimated changes in the hidden tax rate,

\footnotetext{
${ }^{1}$ See Lore Croghan, "Americans' Collective Five-Finger Discount Is a Whopping $\$ 42$ Billion as Recession Boosts Shoplifting: Study," New York Daily News, November 13, 2009; Jacyln Giovis, "Theft Rings Blitz Florida," South Florida Sun-Sentinel, June 10, 2007; and Parija Kavilanz, "Thieves Will Cost You $\$ 423$ at the Mall this Year," CNN Money, October 19, 2010.

${ }^{2}$ Of the slim existing research in marketing, studies either have only briefly referenced the "hidden tax" concept or have cited media coverage without conducting analysis to quantify the phenomenon (Cox, Cox, and Moschis 2009; Mitchell et al. 2009; Wilkes 1978).
} 
we compare the associated welfare costs of larceny crime across product markets.

We show that within five years, enactment of higher felony larceny thresholds causes notable shifts in larceny crime for some product markets. For instance, threshold enactment leads to a 39 percent decrease in the larceny rate for automobiles and a 22 percent increase in the larceny rate for jewelry and purses/wallets. Across product markets, we find baseline pre-enactment hidden tax rates that are fairly small compared with some conventional tax rates, ranging from 0.1 percent to 0.4 percent. These tax rates rise due to increases in larceny crime or fall due to decreases in such crime, with the direction and size of shifts in larceny crime varying by product market. Our findings imply that a 1 percent increase in the larceny rate for a given product market changes the hidden tax rate by 0.7 percent (automobiles) to 1.2 percent (computers). Compared with the welfare implications of changes in some conventional tax rates, exogenous changes in the hidden tax induce state-level welfare changes per year that are minimal, ranging from $-\$ 1,500$ (computers) to $\$ 4,700$ (automobiles) across product markets.

The remainder of the paper is organized as follows. Section 2 discusses the conceptual framework of a hidden larceny tax. Section 3 provides background on felony larceny thresh-

old policy in the United States. Section 4 describes the data on consumer expenditures and larceny crime. Section 5 outlines the strategy for estimating the impact of larceny threshold increases on larceny rates, as well as our approach for determining market prices and quantities, hidden tax rates, and welfare changes. Section 6 presents the findings, and section 7 concludes.

\section{Conceptual Framework}

Larceny crime in a product market can be conceptually characterized as a "hidden tax" that reduces producers' expected per-unit revenue, increases consumers' expected per-unit expenditure, or both. This hidden larceny tax can be depicted as a standard tax that poten- 
tially distorts markets and leads to social welfare changes, depending on market structure and the size of the tax (Auerbach 1985). Thus, changes in the amount of larceny crime can be depicted as a change in the hidden larceny tax.

In this theoretical framework, we assume risk neutrality by producers and consumers regarding how they assess uncertainty and form expectations, as well as an absence of heterogeneity across agents in order to simplify aggregation. We also assume that stolen units will be replaced by an additional purchase if stolen from consumers, and that units stolen from producers would have been sold in the absence of theft. ${ }^{3}$ Lastly, as with a standard tax, the incidence of the hidden tax does not depend on who is "taxed" (that is, whether goods are stolen from consumers or producers).

Figure 1 portrays an increase in the hidden larceny tax from $\tau_{1}$ to $\tau_{2}$ in a product market after an exogenous increase in the larceny rate. ${ }^{4}$ As in standard tax theory, each hidden tax drives a wedge between the prices paid by consumers, $P^{d}$, and the prices received by producers, $P^{s}$. The optimal quantity of the good without larceny crime is $Q$. $N_{1}$ and $N_{2}$ reflect the optimal quantity net of larceny theft quantities, $S_{1}$ and $S_{2}$, respectively. The shaded area in the figure illustrates the increase in deadweight loss that results from the hidden tax increase. In this study, our primary interest lies in determining the size of the hidden tax for each product market before and after an exogenous shift in larceny crime, as well as the change in welfare corresponding to the change in this tax. ${ }^{5}$

\footnotetext{
${ }^{3}$ We do not incorporate other costs to consumers or producers facing the possibility of larceny — for instance, investments in monitoring technology to combat such theft.

${ }^{4}$ Other commodity taxes are omitted for simplicity. The existence of such taxes would lead the government to accrue some welfare gains or losses due to hidden tax changes in the form of changes in tax revenue.

${ }^{5}$ Such welfare calculations will implicitly rely on a static, partial equilibrium model that also assumes Marshallian demand given reliance on estimates of demand elasticities from other papers. Studies suggest that alternative assumptions (that is, a dynamic and/or general equilibrium model, as well as Hicksian demand) would not likely have a large effect on the empirical analysis.
} 


\section{Felony Larceny Thresholds}

This paper looks at changes in felony larceny thresholds as a source of exogenous variation in larceny rates. The felony larceny threshold determines whether a larceny crime can be charged as a felony, thereby affecting the probability of felony conviction. Penalties for felonies in most states involve incarceration for at least one year in state prisons, whereas misdemeanor offenses often carry up to one year in local jails. People with felony convictions may also lose civil liberties, such as the right to vote during or after sentence-serving time, and face difficulties in the labor market afterward due to their felony records. Public policy governing felony larceny thresholds therefore has implications for the punishment severity of the criminal justice system and can affect theft behavior and larceny rates.

State legislation mandates the dollar value of the felony larceny threshold in the United States. Thirty-one US states increased their felony larceny thresholds between 2000 and 2018 as part of criminal justice system reform that aimed to address rising mass incarceration and criminalization (Jackson and Sullivan 2020; Pew Charitable Trusts 2017). ${ }^{6}$ The availability of crime and expenditure data, as detailed in later sections, restricts our analysis to 17 states listed in table A1 and to the 2000-2015 period. We focus on the first enactment after the start of 2000 for each state to avoid double-counting market quantities for Colorado and Louisiana, each of which raised its threshold twice. Figure 2 shows how the first enactments changed the distribution of felony larceny thresholds between 2000 and 2015 for the 17 states in the sample. Threshold values in general increased more than inflation, and the modal threshold value doubled from $\$ 500$ to $\$ 1,000$.

\footnotetext{
${ }^{6}$ Maine is the only state that lowered its threshold during this period (from $\$ 2,000$ to $\$ 1,000$ in 2001 ).
} 


\section{Expenditure and Crime Data}

\subsection{CEX Expenditure Data}

Data on US consumer expenditures come from the Consumer Expenditure Survey (CEX) from 2000 through 2015 (United States Department of Labor 2016), a period that aligns with our crime data (to be described in section 4.2). CEX data are administered by the US Bureau of Labor Statistics (BLS) and contain detailed expenditure-level information on consumer purchases, as recorded by survey responses. These responses are collected every quarter in two surveys: the Interview Survey for major or infrequent purchases, such as automobiles and computers, and the Diary Survey for minor or frequent purchases, such as food and toiletries.

We focus on the Interview Survey because it contains purchase price information for a subset of product categories, such as major appliances and furniture, all of which can be reasonably matched to stolen property categories in our crime data. ${ }^{7}$ Such information allows us to determine typical nominal prices for certain products and then apply these prices to CEX expenditures and larceny stolen values in order to calculate associated quantities. Alternative sources of price information, such as retail scanner data from Nielsen or IRI, are not viable for our analysis since they reflect products that are not narrowly identified, or not identified at all, in our crime data. Additionally, given our focus on "typical" prices (to be defined later), we are not particularly hindered by the inability to identify homogeneous products of the same quality in the CEX (for instance, products with the same barcode).

In order to ensure data quality and alignment with our crime data, we impose some restrictions on the CEX sample. First, because the BLS suppresses or recodes state identifiers in some cases to protect respondent confidentiality, we restrict the sample to 17 states (see Appendix Table A1). These 17 states all changed their larceny thresholds between 2000 and

\footnotetext{
${ }^{7}$ We utilize the CEX public-use microdata files containing individual answers from survey respondents. Purchase price information is from detailed expenditure data (EXPN files). We also use monthly expenditure information (MTBI files) and household information (FMLI files).
} 
2015, meet certain desirable criteria for the crime data (see Jackson 2020 and section 4.2), and have at least some availability of non-recoded state locations in the CEX both before and after threshold enactment. ${ }^{8}$ We also impose additional cross-sectional restrictions, dropping households ("consumer units") with roughly zero food consumption (as in Coibion et al. 2017 and Dynan, Edelberg, and Palumbo 2009) or with multiple state locations over time. ${ }^{9}$ Lastly, as a temporal restriction, we omit data from the first quarters of 2005 and 2015 due to sample adjustments related to the 2000 and 2010 decennial censuses, respectively. ${ }^{10}$

\subsection{NIBRS Crime Data}

We use crime data from the National Incident-Based Reporting System (NIBRS) from 2000 through 2015 (National Archive of Criminal Justice Data 2018). NIBRS data contain detailed information on crime incidents reported to law enforcement agencies, or "jurisdictions." Our sample includes only jurisdictions that likely represent the same geographic areas over time and have crime data and CEX state location information throughout the pre-enactment and post-enactment periods. Such jurisdictions correspond to 17 states.

We restrict our sample to theft incidents with stolen values lying between the old and new felony larceny thresholds of each state, namely the "response region." We focus on the response region because the effect of enactment on incentives to commit larcenies should theoretically be strongest in this part of the stolen value distribution, since larcenies in the response region switch from being generally felony-eligible to being generally felony-ineligible. Focusing on the response region also minimizes confounding effects of penalty brackets outside of the response region, as policymakers often adjust the felony larceny thresholds and

\footnotetext{
${ }^{8}$ We drop five states from the sample of 22 states analyzed in Jackson (2020) due to insufficient state location information in the CEX: Arkansas, Mississippi, Montana, North Dakota, and South Dakota.

9 "Zero-food" households are those reporting less than $\$ 1$ of food consumption in any household-interviewmonth observation in the 2000-2015 MTBI files. "Multiple-state" households all report two locations over time and comprise only 0.2 percent of households in the 2000-2015 FMLI files.

${ }^{10}$ In 2005:Q1 and 2015:Q1, as a result of census-related sample adjustments, CEX weights for households do not sum to the total number of households in the US population. At the cost of precision, we drop these two periods from our analysis to eliminate bias in the event that CEX households in these periods differ non-randomly from CEX households in other periods within the 2000-2015 time frame.
} 
other "within-felony" and "within-misdemeanor" penalty thresholds simultaneously. We widen the response region by a $\$ 1$ buffer (from $\$ 1$ below the old larceny threshold of each state to $\$ 1$ above the new larceny threshold) to allow for minimal miscalculation of stolen values and varying definitions of penalty thresholds across states. ${ }^{11}$

We also impose incident-level restrictions besides limiting stolen values to the response region. Specifically, we omit larceny crimes that can be exempt from the general larceny threshold rule given available information on the offenders, victims, stolen properties, or incidents. We further exclude larceny incidents involving unidentified stolen properties, because we do not know if the properties would exempt the crime from the threshold rule. We exclude theft incidents (both larceny and non-larceny) with unknown values of stolen properties because we cannot impose response region restrictions on such incidents. We also exclude theft incidents that involve attempted offenses, multiple offenses, or multiple stolen property types, as well as incidents for which we know only the report dates as opposed to the incident dates. Overall, we implement data cleaning criteria similar to those in Jackson (2020). We focus on larceny cases with exclusively individual victims or exclusively business victims in order to ensure clear construction of the hidden tax rate.

We divide stolen properties described in NIBRS data into 13 property types, as detailed in Table A3. Figure 3 characterizes the distribution of those property types in larceny incidents before and after we restrict the sample to the response region. The distributions of stolen properties for larceny misdemeanors versus felonies are more similar after we impose the response region restriction, as extreme-value properties such as miscellaneous durables and automobiles tend to lie outside the region. Among larceny cases likely most affected by changes in larceny thresholds, automobiles are the most commonly stolen property, followed by vehicle parts. Theft of money and theft of tools and other durables are also common.

\footnotetext{
${ }^{11}$ The listed felony larceny threshold refers to the smallest stolen property value generally eligible for a felony conviction in some states, and the largest value generally eligible for a misdemeanor conviction in other states.
} 


\section{Estimation}

\subsection{Identifying the Long-Run Impact of Larceny Threshold Change on Crime}

We estimate the effect of increases in felony larceny thresholds on daily jurisdiction larceny rates. We identify the effect using difference-in-differences (DD), focusing on 1,800 days before and 1,800 days after the enactment of threshold changes. This time frame allows us to study long-run shifts in larceny rates and hidden tax rates, which likely result in permanent changes in the quantity of a product exchanged. The control group for larceny incidents includes non-larceny theft incidents, namely burglary, robbery, and other kinds of theft. $^{12}$

Specifically, the reduced form equation for jurisdiction $j$ on day $t$ is:

$$
R A T E_{j t}=\zeta+\eta E N A C T_{j t}+\lambda L A R C E N Y_{j t}+\pi\left(E N A C T_{j t} \times L A R C E N Y_{j t}\right)+\mathbf{X}_{j t}^{\prime} \omega+\nu_{j t}
$$

where RATE is the crime rate, ENACT indicates the post-enactment period, $L A R C E N Y$ indicates a larceny outcome, $\mathbf{X}$ is a vector of control variables that vary across jurisdictiondays (but stay constant within a jurisdiction-day), and $\nu$ is the error term. We focus on the OLS estimation of $\pi$ for each product market. We weight the crime rate outcome using the estimated inverse probability of an observation being in the treatment or control group in order to further address non-random selection of larceny incidents in the treatment group (see Jackson 2020). We also weight the regressions by jurisdiction population and cluster standard errors at the jurisdiction level.

\footnotetext{
${ }^{12}$ We consider counterfeiting/forgery, embezzlement, extortion/blackmail, fraud, kidnapping/abduction, stolen property offenses, and bribery as types of theft, since each incident of such crimes has an associated stolen value in the NIBRS data.
} 


\subsection{Determining Product Market Prices and Quantities}

\subsubsection{CEX Prices}

As discussed in section 4, we use the CEX data to calculate typical nominal prices. Such prices are then used to determine associated quantities from CEX expenditures and NIBRS stolen values. We focus on CEX product categories - major and minor appliances, clothing, sewing materials, furniture, and vehicles - that have purchase price information and can be reasonably matched to broad NIBRS stolen property categories, or "product markets" (see Appendix Tables A2 and A3). ${ }^{13}$

We examine the distribution of nominal prices available in the narrow CEX product descriptions, confirming that these distributions generally align with ranges of retail prices (using websites of retailers such as Walmart). ${ }^{14}$ Given such price variation and potential differences in item quality even within narrow CEX product descriptions, we focus on "typical" prices instead, using the median price. ${ }^{15}$ Appendix Table A2 displays these typical nominal prices for the narrow product descriptions when the sample restrictions noted in section 4 are applied, as well as when purchase timing and maximum prices are restricted in light of felony larceny threshold legislation. ${ }^{16}$ We focus on nominal prices without adjusting

\footnotetext{
${ }^{13}$ We create a crosswalk file to match CEX product categories with NIBRS stolen property categories. First, to determine 2000-2015 typical purchase prices for products at the level of a CEX Universal Classification Code (UCC), we align UCC product identifiers (available for all expenditures in the 2000-2015 MTBI files) with EXPN product identifiers (available for all purchase prices in the 2000-2015 EXPN files and all expenditures in the 2010-2015 MTBI files). This match allows us to link CEX prices and expenditures across the EXPN and MTBI files for the entirety of the 2000-2015 period. Second, we then match these CEX product categories to broadly defined property categories, aggregated from individual NIBRS stolen property descriptions.

${ }^{14}$ Unfortunately, we cannot compare the CEX prices with Consumer Price Index average price data from the BLS, as the latter are limited to household fuels, gasoline, and food items, none of which has purchase price information in the CEX.

${ }^{15}$ Using the median rather than the average also helps address potential outliers in the right tail of a product's price distribution due to respondents misinterpreting the purchase price survey inquiry and reporting expenditures instead.

${ }^{16}$ Purchases are constrained to (1) those occurring during state-specific pre-enactment periods and (2) those with prices below a state-specific maximum. Each state-specific maximum price equals the new felony larceny threshold minus $\$ 1$ (since for some states, the larceny threshold is the lowest felony value rather than the highest misdemeanor value). This restriction prevents cases in which, even if only one unit of the product were stolen at the median price, the associated stolen value would fall outside of our focal range between the old and new larceny thresholds. See Appendix Table A1 for the relevant larceny threshold policy information.
} 
for inflation to align with felony larceny threshold legislation, and to obtain a more accurate determination of the associated quantities purchased at a given time. We also assume that the typical price reflects the cost of a "standard" unit for each product. For instance, when documenting monthly average prices for food, utilities, and fuel, the BLS lists a "standard size" of one pound for ground beef, eight ounces for yogurt, and one dozen for eggs. ${ }^{17}$

It is of interest to examine how imposing the maximum price affects the price distribution, since by definition it is the sole data restriction tied to price levels. Let $P_{1}$ reflect the typical price for some product or product market calculated using CEX data under all of the aforementioned sample and purchase restrictions. In contrast, $P_{1 u}$ is the analogous "unrestricted" price, which relaxes the state-specific maximum-price constraint. The upper plots of Figure 4 compare $P_{1}$ and $P_{1 u}$ for automobiles, a product market in which the maximumprice constraint is likely binding. ${ }^{18}$ As expected, we can observe a distinct difference in the maximum log price across the two distributions, although the skew is similar.

It is also worthwhile to examine how prices in the CEX and NIBRS data compare. The prices associated with the CEX expenditures reflect goods that are either never stolen or eventually stolen from consumers, while the prices associated with the NIBRS larceny values that we focus on reflect goods that are stolen from consumers or producers. Thus, we might expect partial but not full alignment of the distributions, especially if stolen goods are differentially selected in terms of price, or if the sample of NIBRS goods stolen from consumers differs from the sample of CEX goods that are eventually stolen from consumers. We can perform this exercise with automobiles since they are the only product in the NIBRS for which we can observe the quantity stolen, thus allowing us to determine restricted and

\footnotetext{
${ }^{17}$ See the fact sheet "CPI: Average price data" on the BLS website from April 24, 2019.

${ }^{18}$ To estimate purchase prices in the CEX for the automobile product market, an additional step is necessary compared with the other CEX product categories. We use the CEX NETPURX measure ("Net purchase price after discount, trade-in, or rebate, including destination fee"). We estimate the purchase price as NETPURX + TRADEX, where the latter measure is the "amount of trade-in allowance" (further information is not available to add back other price deductions). We opt for NETPURX rather than QTRADEX, an alternative automobile price measure in the CEX, because the former more closely aligns with examined historical Kelley Blue Book values, which we use as an additional price validity check.
} 
unrestricted nominal prices using NIBRS data, $P_{1}^{n}$ and $P_{1 u}^{n}$, respectively. ${ }^{19}$ Comparing the upper and lower plots of Figure 4 indeed shows similarity between the CEX and NIBRS nominal automobile prices, especially when prices are restricted. However, unrestricted prices indicate that the automobiles in the NIBRS data tend to be priced somewhat lower than those in the CEX. Still, the similarity between the CEX and NIBRS restricted price distributions suggests that applying CEX prices to NIBRS stolen values is a reasonable approach to determining associated stolen quantities.

\subsubsection{CEX and NIBRS Quantities}

Given CEX typical prices, $P_{1}$, we can determine the related CEX and NIBRS quantities, since these data sets contain product expenditures and stolen values, respectively. For each product market, we define the pre-enactment CEX expenditure, $E_{1}$, and the pre-enactment CEX quantity sold, $X_{1}$. Since we observe $E_{1}$ and derive $P_{1}$, we can obtain $X_{1}=E_{1} / P_{1}$. Additionally, since the CEX is a consumer survey, we further decompose this quantity as $X_{1}=N_{1}+S_{1}^{d}$. $N_{1}$ is the quantity sold but not stolen, and $S_{1}^{d}$ is the quantity stolen from consumers (proxied using NIBRS individual victims). We apply CEX household weights so that quantity measures are representative of the population in our 17 analyzed states. We then focus on quantity measures that are annualized state-level averages. ${ }^{20}$

Similarly, for each product market, we define the pre-enactment NIBRS larceny stolen value, $V_{1}$, as reflecting larcenies from consumers or producers (where the latter is proxied using NIBRS business victims). We also define the pre-enactment NIBRS larceny stolen quantity, $S_{1}$. Since we observe $V_{1}$ and derive $P_{1}$ from the CEX, we can obtain $S_{1}=V_{1} / P_{1}$.

\footnotetext{
${ }^{19}$ As indicated in Appendix Table A3 and to help ensure alignment between the CEX and NIBRS data sets, we define the automobile product market to include NIBRS stolen properties for automobiles and trucks. For simplicity in Figure 4, we focus on NIBRS incidents in which only one such motor vehicle was stolen, which reflects 99 percent of cases in the raw data.

${ }^{20} \mathrm{We}$ also apply a scaling factor to adjust the final quantity measures. This scaling factor is based on the ratio of expenditures with restricted prices versus expenditures with unrestricted prices. Since we cannot restrict the expenditures themselves (because prices are not linked to each expenditure, as reflected by our crosswalk approach), such scaling is necessary to prevent the calculated quantities from being too high given maximum prices imposed.
} 
We can likewise define $S_{1}^{d}=V_{1}^{d} / P_{1}$ and $S_{1}^{s}=V_{1}^{s} / P_{1}$ as quantities stolen from consumers and producers, respectively. Thus, $S_{1}=S_{1}^{d}+S_{1}^{s}$. We weight the quantities by the NIBRS coverage rate in our 17-state sample to obtain a measure that reflects the population of the whole sample and then calculate the annualized state-level average quantities.

\subsection{Determining the Hidden Tax}

We can calculate the pre-enactment hidden tax rate, $\tau_{1}$, induced by larceny crimes for each market as the proportion of goods stolen from sellers and buyers. Assuming that the efficient market quantity in the absence of theft would be constant over time, we can measure the efficient quantity sold using pre-enactment variables as: $Q=X_{1}+S_{1}^{s}$, with $d Q=0$. Then the pre-enactment hidden tax induced by larceny is $\tau_{1}=S_{1} / Q$. This calculation reflects a variation of the standard tax incidence "equivalence" result: The size of the hidden tax (and the resulting tax incidence) does not depend on whether the unit is stolen from consumers or from producers, conditional on it being stolen.

We proceed to derive the change in the hidden tax following enactment-induced changes in the larceny rate for each product market. We define the annualized larceny rate as the annualized count of larceny incidents divided by the population (in millions), $l=L / M .^{21}$ Then the change in larceny rate following enactment is:

$$
d l=d \frac{L}{M}=\frac{M d L-L d M}{M^{2}}=\frac{M d L}{M^{2}}=\frac{d L}{M},
$$

assuming population varies nominally over time $(d M=0)$. Thus $d L=M d l$.

Suppose $\pi$ is the coefficient estimating the effect of enactment on the daily larceny rate for a given jurisdiction. We can estimate the annualized change in the larceny rate as $d l=365 \pi$. Thus, $d L=M d l=M \times 365 \pi$. We take $M$ as the average state population in the enactment year. Thus, $d L$ is the annual average change in larceny incidents as a result of enactment,

\footnotetext{
${ }^{21}$ We use annualized variables because the time horizon for our welfare calculations is annual.
} 
assuming the larceny rate in jurisdictions not covered by NIBRS is similar to the larceny rate in NIBRS jurisdictions.

Now consider the change in the hidden tax following enactment (note that $d Q=0$ ):

$$
d \tau=d \frac{S_{1}}{Q}=\frac{Q d S-S_{1} d Q}{Q^{2}}=\frac{d S}{Q}
$$

Here, $d S$ is the total effect of enactment on stolen quantities across all incidents. We can estimate $d S$ as the total effect of enactment on the larceny count $(d L)$ multiplied by a measure, $s_{1}$, of the pre-enactment "typical" stolen quantity per incident: $d S=s_{1} d L=$ $s_{1} \times 365 M \pi$. In order to reduce the influence of potential outliers, we take $s_{1}$ as the median stolen quantity and compute $s_{1}=v_{1} / P_{1}$, where $v_{1}$ is the median stolen value across all incidents in the pre-enactment NIBRS sample.

Thus, for a given product market, the estimated change in the hidden tax rate induced by a shift in larceny crime following a felony larceny threshold change is:

$$
d \tau=\frac{d S}{Q}=\frac{s_{1} M \times 365 \pi}{Q}
$$

and we can derive the post-enactment tax as $\tau_{2}=\tau_{1}+d \tau$.

\subsection{Calculating Welfare}

We can determine the expected welfare impact of the exogenous change in the hidden larceny tax by treating the larceny tax as a traditional tax in a standard public finance framework. As described generally by Auerbach (1985) and illustrated by Figure 1 for the case of a hidden tax increase, the welfare change of interest is a trapezoidal area reflecting the difference in two Harberger (1964) triangles of deadweight loss. ${ }^{22}$

\footnotetext{
${ }^{22}$ This geometric interpretation aligns with a second-order Taylor approximation of deadweight loss, rather than an exact calculation. Such approximations require less information regarding market structure and have been found by some empirical studies to result in deadweight loss estimates that are close to exact measures (Auerbach 1985).
} 
First, as summarized by Kotlikoff and Summers (1987), we outline an expression for the change in price paid by consumers following a change in the tax rate: $d P^{d}=\left[\eta^{s} /\left(\eta^{s}-\eta^{d}\right)\right] d \tau$. Here, $\eta^{s} \geq 0$ and $\eta^{d} \leq 0$ are price elasticities of supply and demand, respectively, and the expression holds exactly locally and approximately non-locally. We further derive $d N=$ $\eta^{d} N_{1} d P^{d}$, which follows from the general formula for the price elasticity of demand. ${ }^{23}$ The sign of $d N$ will depend on whether crime increases $\left(N_{2}<N_{1}\right)$ or decreases $\left(N_{1}<N_{2}\right)$ following larceny threshold enactment.

Using the geometric formula for the area of a trapezoid and further multiplying by $P_{1}$ to express the welfare change in nominal US dollars (since the hidden taxes are expressed in percentage terms rather than price units, as an excise tax is), we derive a formula for the change in welfare, $d O$ :

$$
d O=\frac{1}{2}\left(\tau_{1}+\tau_{2}\right) P_{1} d N
$$

Alternatively, if we do not multiply by $P_{1}$, we obtain a welfare change expression that focuses on quantity shifts - namely, the average quantity change corresponding to a given welfare change. These calculations concern only the welfare impact of the change in the hidden tax, disregarding other welfare-relevant factors, such as incarceration (considered in Jackson 2020).

\section{Main Results}

\subsection{Crime across Product Markets}

In order to examine whether identification is achieved, we look at 360-day period DD coefficients in a dynamic analog of equation (1) and test whether they are jointly equal to 0 . Table 1 reports the results from estimating equation (1) for all stolen properties and the 10 out of

\footnotetext{
${ }^{23}$ Normally, the expression for $d N$ would also be divided by $P_{1}$, thereby reflecting a $d P / P$ term corresponding to the percentage increase in price due to the tax. However, since the hidden tax change is already expressed in percentage terms (recall that $d \tau=d S / Q$, the percentage of the efficient market quantity accounted for by a change in the larceny stolen quantity), dividing by price is not necessary.
} 
13 property types that pass the F-test at the 5 percent significance level, together with the F-test p-values. Although the estimated effect of enactment on the larceny rate for the whole sample is not statistically significant, the effect differs across stolen property types. Five of eleven coefficients for individual property types are significant at the 5 percent level. Raising the felony larceny threshold in the long run increases response-region daily larceny rates for computer software/hardware, merchandise, jewelry and purses/wallets, and equipment and miscellaneous vehicles, but it reduces the rate for automobiles. ${ }^{24}$ These estimated changes in larceny rates range from -0.118 (automobiles) to 0.166 (equipment and miscellaneous vehicles). Figure 5 illustrates pre-enactment parallel trends and dynamic post-enactment effects for the five stolen property types with significant estimated effect coefficients.

It is unclear why larceny crime rises in some product markets but falls in others following an increase in the felony larceny threshold. One possible explanation is that larceny of a specific property type can correlate with certain characteristics of the labor market or of the offenders. For instance, Jackson (2020) shows that following felony larceny threshold increases, low-wage labor markets experience a long-run decline in larceny rates, while high-wage labor markets experience a long-run rise in rates. Thus, certain characteristics that differ across product markets may affect the ability of offenders to take advantage of employment opportunities that arise as the probability of felony conviction decreases.

\subsection{Hidden Tax}

Of the 11 product markets examined in Table 1, we focus attention on the subset with significant coefficients at the 5 percent level (as displayed in Figure 5) and available CEX data on purchase prices. This criterion results in four product markets for which we calculate hidden tax rates, shown in Table 2. The table also displays annual market prices and quantities exchanged for the average state in our sample. More market transactions occur for equipment and miscellaneous vehicles and jewelry and purses/wallets than for automobiles

\footnotetext{
${ }^{24}$ Purses and wallets refer to the objects themselves, excluding properties such as money or credit cards that are stolen along with the objects, as NIBRS lists stolen purses/wallets separately from their contents.
} 
and computer hardware/software. We also observe in the NIBRS a much larger quantity of goods stolen from consumers compared with the quantity stolen from producers. Our estimates of the pre-enactment hidden tax rate in the response region range from 0.11 percent (jewelry) to 0.42 percent (automobiles) across product markets, changing to a range of 0.14 percent (jewelry) to 0.30 percent (automobiles) following enactment.

These estimated hidden tax rates are smaller than some conventional tax rates. ${ }^{25}$ However, the hidden tax rates are broadly consistent with what one might expect given market data on "shrinkage," the inventory loss from retail. Shrinkage accounted for 1.33 percent and 1.38 percent of retail sales in 2018 and 2019, respectively. ${ }^{26}$ The definition of shrinkage, however, does not conceptually align with our hidden tax definition, even if one focuses solely on the share of shrinkage due to shoplifting, which is slightly more than one-third. ${ }^{27}$ NIBRS data may reflect only a subset of such incidents since they may not all be reported, which would cause our pre-enactment hidden tax rates to be smaller than shoplifting shrinkage estimates. Our focus on incidents within the response region of stolen values might also contribute to relatively smaller hidden tax estimates. Conversely, our hidden tax rates reflect larceny incidents from consumers as well as producers, which would cause hidden tax estimates to be larger than shoplifting shrinkage estimates. The net effect of these opposing factors is unclear, so our hidden tax rate estimates are reasonable.

The estimated increase in the tax rate is fairly large, ranging in absolute value from 18 percent to 100 percent across product markets. Given the small pre-enactment hidden tax rates, the size of such tax rate growth should not be overemphasized. Nevertheless, if we want to further evaluate these growth values, we can also consider the exogenous increases in

\footnotetext{
${ }^{25}$ For instance, the sales tax rate in Massachusetts is 6.25 percent, applicable to all four product markets we examine (see the guide "Sales and Use Tax" from the Mass.gov website).

${ }^{26}$ See TJ McCue, "Inventory Shrink Cost the US Retail Industry \$46.8 Billion," Forbes, January 31, 2019; and Matthew Hudson, "The Top Sources of Retail Shrinkage," The Balance Small Business, February 2, 2020.

${ }^{27}$ See Kiera Abbamonte, "Loss Prevention: 4 Types of Retail Shrinkage and How to Prevent Them," Shopify, August 1, 2018. Besides shoplifting, shrinkage typically occurs due to employee theft, administrative error, or fraud. Although employee theft may qualify as a larceny if reported, such theft may also be less likely to be reported and instead resolved internally by the employer. Thus, we focus solely on shoplifting in our comparison.
} 
larceny rates given by the coefficients in Table 1, expressed as a percentage of the applicable pre-enactment mean. In light of the estimated hidden tax growth, our findings suggest that a 1 percent increase in the larceny rate for a given product market changes the hidden tax rate by 0.7 percent (automobiles) to 1.2 percent (computers), a response in the range of unit elasticity.

\subsection{Welfare}

Table 3 displays the estimated changes in state-level annual welfare due to exogenous changes in the hidden tax. We assume that product supply is perfectly elastic, consistent with the limited estimates we find in the literature for our product markets of interest. Thus, in our analysis the change in price paid by consumers will be equal to the change in the hidden tax, and the full incidence of the hidden tax, including any excess burden, is assumed to be borne by consumers. ${ }^{28}$

Our estimates of state-level annual welfare changes in the response region are relatively small. ${ }^{29}$ The largest positive change is a $\$ 4,651$ welfare increase in the automobile market, corresponding to a 29 percent annual fall in the hidden tax rate. In contrast, the largest negative change is a $\$ 1,487$ decrease in the computer market, corresponding to a 50 percent annual rise in the hidden tax rate. These welfare changes are notably smaller than analogous estimates from some studies examining changes in conventional tax rates. ${ }^{30}$ Additionally, the average quantity change is the largest in the computer market in part because it has the largest demand elasticity estimate. Thus, there does not seem to be evidence of a large welfare impact from enactment-driven exogenous shifts in larceny crime through the hidden

\footnotetext{
${ }^{28} \mathrm{~A}$ departure from perfectly elastic supply, as may be the case in reality, would result in some welfare costs of the hidden tax being borne by producers as well. Additionally, if we were to incorporate some existing excise tax into our analysis, then state governments would also experience welfare gains or losses from the hidden tax.

${ }^{29}$ In contrast, in a back-of-the-envelope cost-benefit analysis of the annual welfare impact of a state raising its felony larceny threshold (for response-region incidents in high-wage areas only, and not considering hidden tax rates or their effects), Jackson (2020) finds a cost from crime escalation of $\$ 0.9$ million and a benefit from incarceration savings of $\$ 3.1$ million.

${ }^{30}$ For instance, estimates from Feldstein (1999) suggest that a 10 percent increase in all personal income tax rates would reduce US welfare by $\$ 43$ billion - that is, $\$ 4.3$ billion per state on average.
} 
tax mechanism.

\section{Conclusion}

Using policy-driven changes in felony larceny thresholds as a source of exogenous variation in larceny crime, this paper examines the changes in hidden tax rates and welfare as the result of shifting larceny behavior. Within the response-region subset of larceny incidents in our sample covering 17 US states during the 2000-2015 period, the estimated pre-enactment hidden tax rate ranged from 0.11 to 0.42 . Raising felony larceny thresholds led to a 0.12 percentage point decrease in the hidden tax rate in the automobile market and a 0.03 to 0.07 percentage point increase across three other product markets - computer hardware/software, equipment and miscellaneous vehicles, and jewelry and purses/wallets. Such changes in the hidden tax imply a $\$ 4,700$ annual gain in welfare in each state for the automobile market and a $\$ 35$ to $\$ 1,500$ annual loss for the remaining three product markets.

Our findings suggest that changes in the hidden tax resulting from exogenous increases in larceny crime do not have a large welfare impact, and such impact can differ across product markets. Future research on the hidden larceny tax can, alternatively, estimate the incidence of the tax for consumers and producers via quasi-experimental analysis instead of using preexisting elasticity estimates. Geographic disparities in the hidden tax and associated welfare implications would also be an interesting area for further study. 


\section{References}

Auerbach, Alan J. 1985. "The Theory of Excess Burden and Optimal Taxation." In Auerbach, Alan J. and Martin Feldstein, eds., Handbook of Public Economics, Vol. 1, Amsterdam: Elsevier.

Batchelor, Roy, and David Gulle. 1995. "Jewellery Demand and the Price of Gold." Resources Policy 21(1): 37-42.

Berry, Steven, James Levinsohn, and Ariel Pakes. 1995. "Automobile Prices in Market Equilibrium." Econometrica 63(4): 841-890.

Coibion, Olivier, Yuriy Gorodnichenko, Lorenz Kueng, and John Silvia. 2017. "Innocent Bystanders? Monetary Policy and Inequality in the U.S." Journal of Monetary Economics 88(June): 70-89.

Cox, Dena, Anthony D. Cox, and George P. Moschis. 2009. "When Consumer Behavior Goes Bad: An Investigation of Adolescent Shoplifting." Journal of Consumer Research 17(2): 149-159.

Dynan, Karen E., Wendy Edelberg, and Michael G. Palumbo. 2009. "The Effects of Population Aging on the Relationship among Aggregate Consumption, Saving, and Income." American Economic Review: Papers 6 Proceedings 99(2): 380-386.

Feldstein, Martin. 1999. "Tax Avoidance and the Deadweight Loss of the Income Tax." Review of Economics and Statistics 81(4): 674-680.

Harberger, Arnold. 1964. "Taxation, Resource Allocation, and Welfare." In The Role of Direct and Indirect Taxes in the Federal Reserve System, edited by NBER and the Brookings Institution, 25-80. Princeton, NJ: Princeton University Press.

Jackson, Osborne. 2020. "Punishment and Crime: The Impact of Felony Conviction on Criminal Activity." Research Department Working Paper 20-1. Boston, MA: Federal Reserve Bank of Boston.

Jackson, Osborne, and Riley Sullivan. 2020. "The Impact of Felony Larceny Thresholds on Crime in New England." New England Public Policy Center Research Report 20-1. Boston, MA: Federal Reserve Bank of Boston.

Kotlikoff, Laurence J., and Lawrence H. Summers. 1987. "Tax Incidence." In Auerbach, Alan J. and Martin Feldstein, eds., Handbook of Public Economics, Vol. 2, Amsterdam: Elsevier.

McCarthy, Patrick S. 1996. "Market Price and Income Elasticities of New Vehicle Demands." Review of Economics and Statistics 78(3): 543-547.

Mitchell, Vince W., George Balabanis, Bodo B. Schlegelmilch, and T. Bettina Cornwell. 2009. "Measuring Unethical Consumer Behavior across Four Countries." Journal of Business Ethics 88(2): 395-412. 
National Archive of Criminal Justice Data. 2018. "National Incident-Based Reporting System, 2000-2015: Extract Files." Ann Arbor, MI: Inter-university Consortium for Political and Social Research [distributor], 2009-09-14-2018-10-05.

Pew Charitable Trusts. 2017. "The Effects of Changing Felony Theft Thresholds." Chartbook, April. Philadelphia, PA: The Pew Charitable Trusts.

Rosenmerkel, Sean, Matthew Durose, and Donald Farole Jr. 2009. "Felony Sentences in State Courts, 2006." Bureau of Justice Statistics Statistical Tables. Washington, DC: Bureau of Justice Statistics.

Stavins, Joanna. 1997. "Estimating Demand Elasticities in a Differentiated Product Industry: The Personal Computer Market." Journal of Economics and Business 49(4): 347-367.

United States Department of Agriculture. 2005. "International Food Consumption Patterns: Table 3 (Compensated Own-Price, Constant Real Income)." Economic Research Service.

United States Department of Labor. 2016. "Consumer Expenditure Survey, 2000-2015." Bureau of Labor Statistics.

Wilkes, Robert E. 1978. "Fraudulent Behavior by Consumers." Journal of Marketing 42(4): $67-75$. 


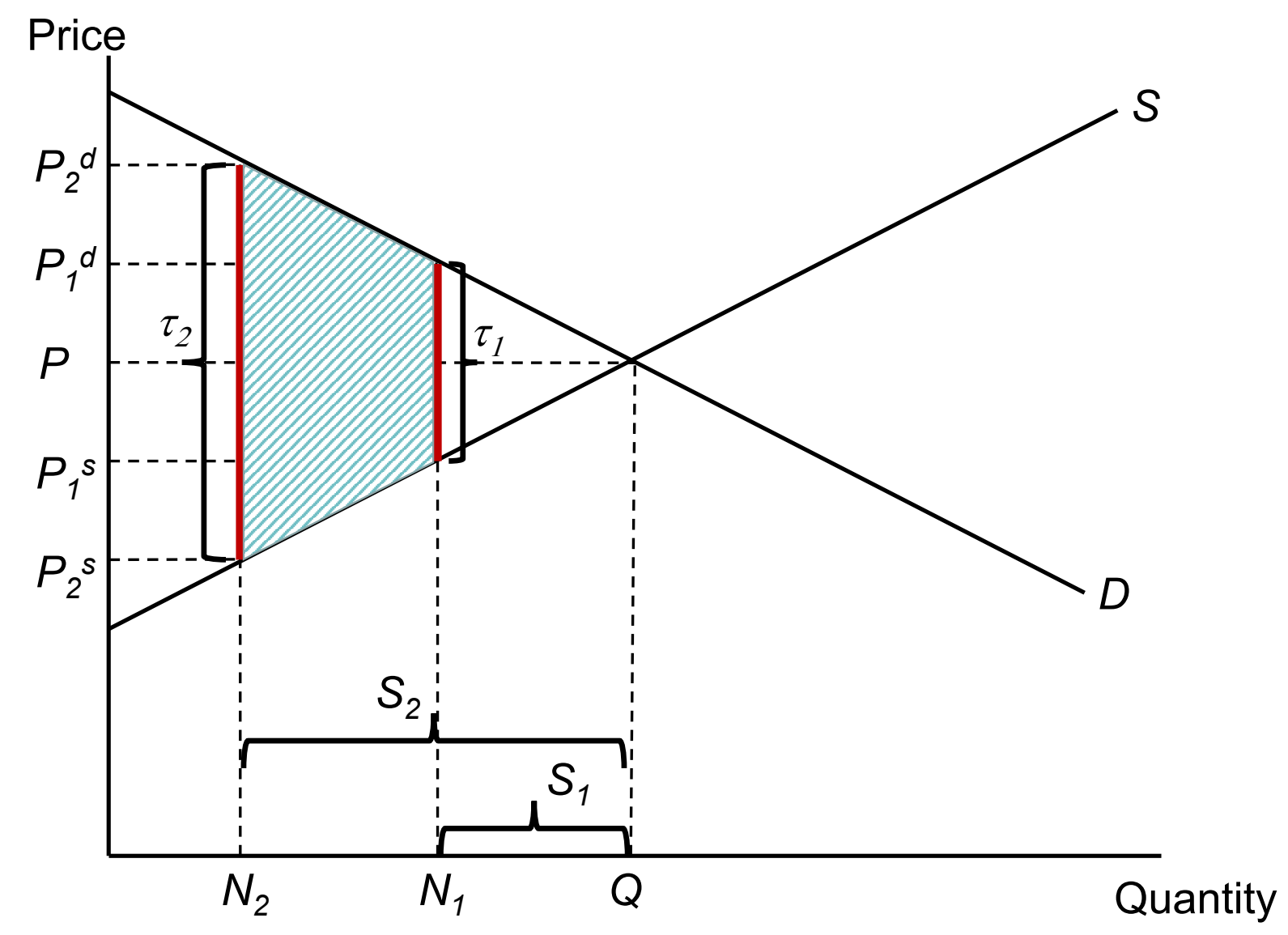

Figure 1: An Increase in the Hidden Larceny Tax Source(s): Authors' illustration. 
Distribution of Felony Larceny Thresholds in 2000



Distribution of Felony Larceny Thresholds in 2015

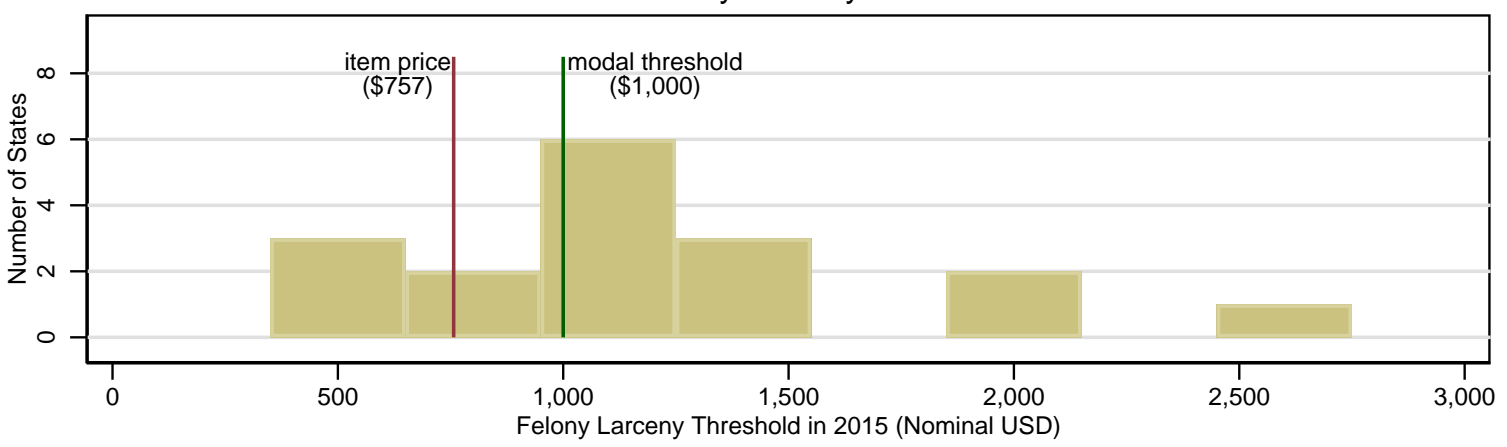

Figure 2: Variation in Larceny Thresholds, Before and After Enactment

Source(s): State legislation, Bureau of Labor Statistics' Consumer Price Index inflation calculator, and authors' calculations.

Note(s): "Item price" reflects a hypothetical product with a constant real value over time. 

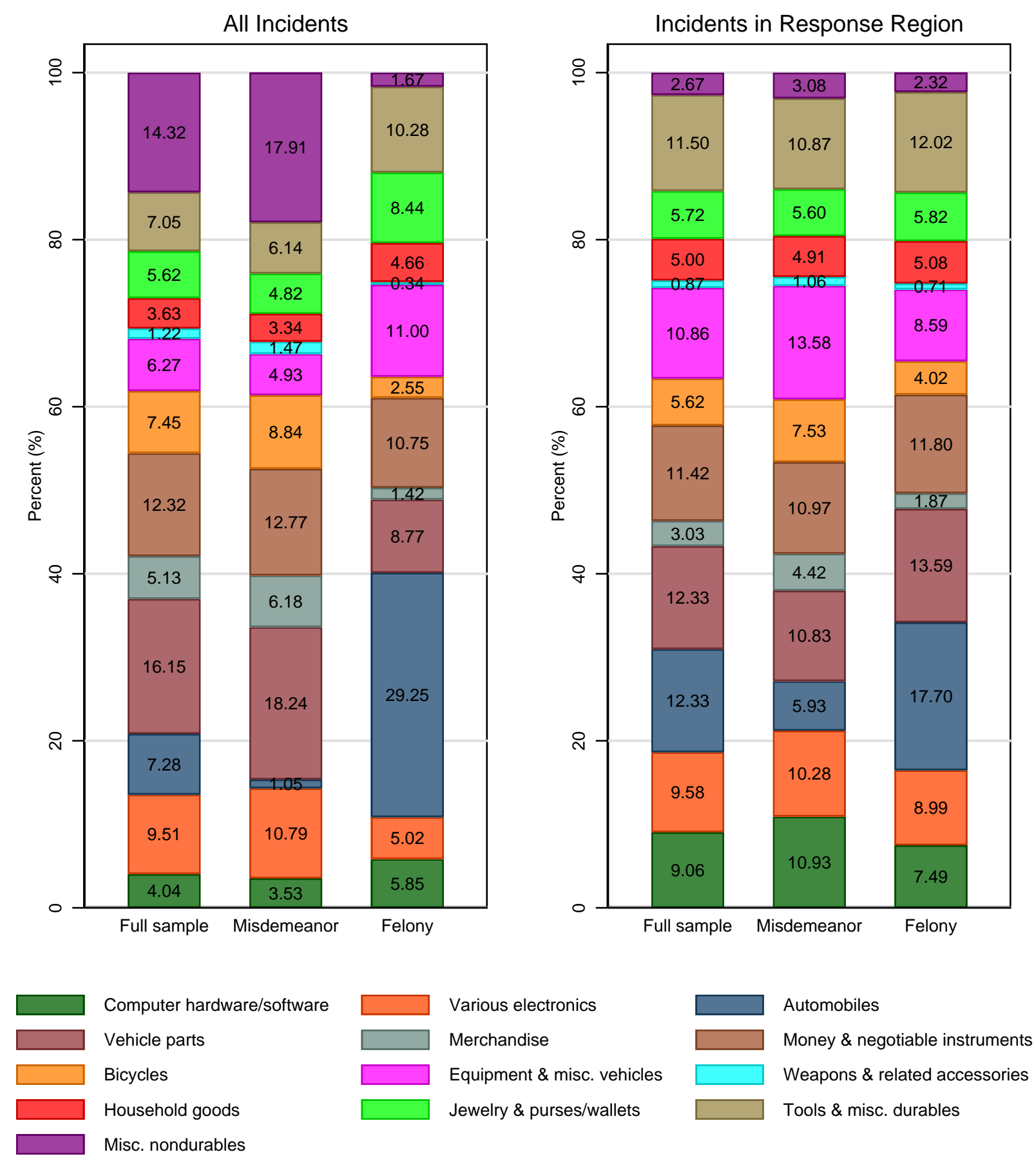

Figure 3: Decomposition of Felony and Misdemeanor Larceny across Product Markets Source(s): State legislation, 2000-2015 National Incident-Based Reporting System data, and authors' calculations. 



Figure 4: Distribution of Automobile Prices, 2000-2015: CEX vs. NIBRS

Source(s): 2000-2015 National Incident-Based Reporting System data, 2000-2015 Consumer Expenditure Survey data, and authors' calculations.

Note(s): Upper plots reflect the Consumer Expenditure Survey (CEX) data, while lower plots reflect the

National Incident-Based Reporting System (NIBRS) data. "Restricted" plots impose state-specific maximum prices set at new larceny thresholds minus $\$ 1$. "Unrestricted" plots do not impose a maximum price. 

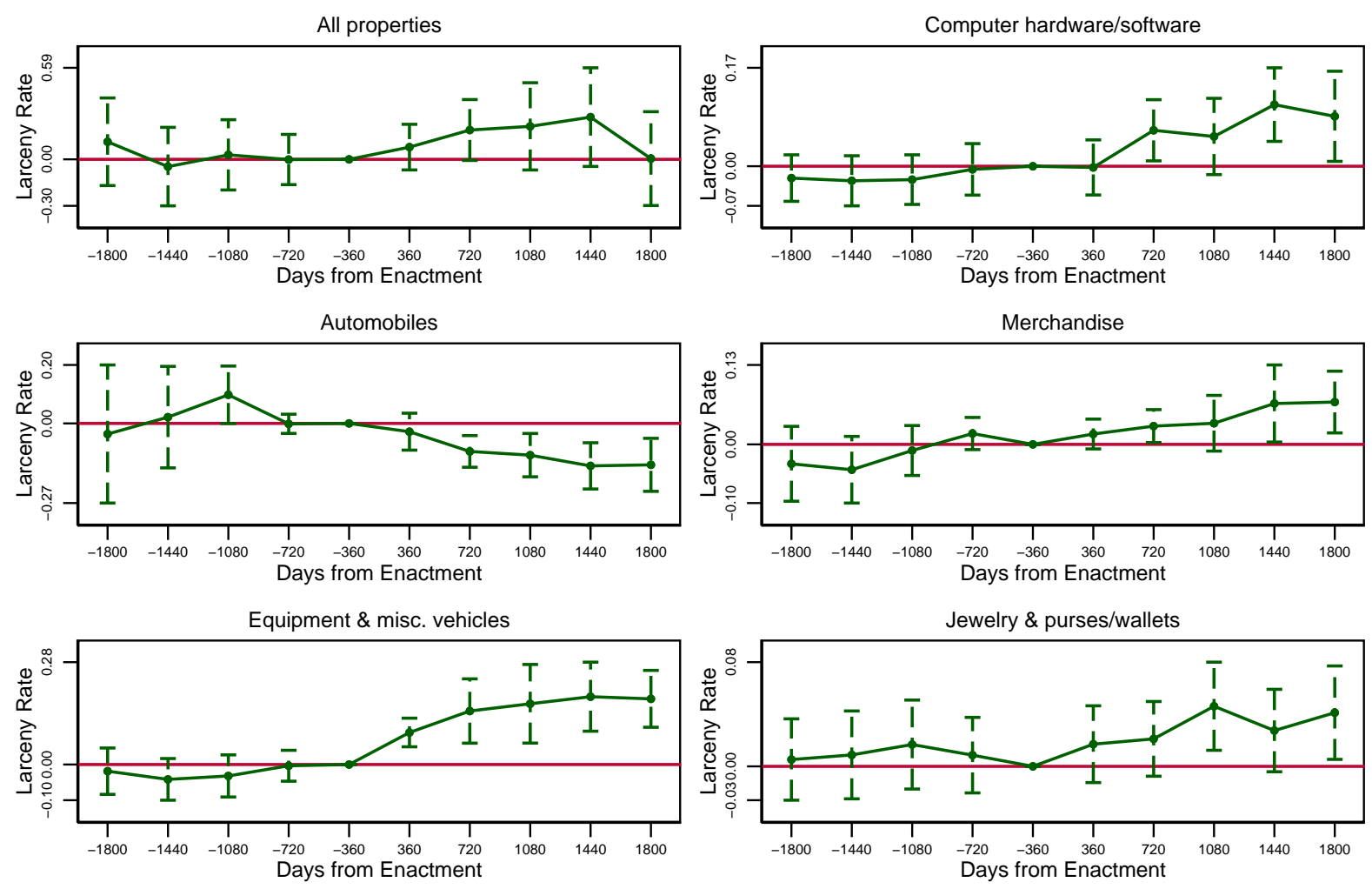

$\vdash ー-ー \dashv 95 \%$ Confidence Interval

Estimated Coefficient

Figure 5: Testing DD Pre-Period Parallel Trends Larceny Rate for Different Product Markets (IPW)

Source(s): State legislation, 2000-2015 National Incident-Based Reporting System data, and authors' calculations. 


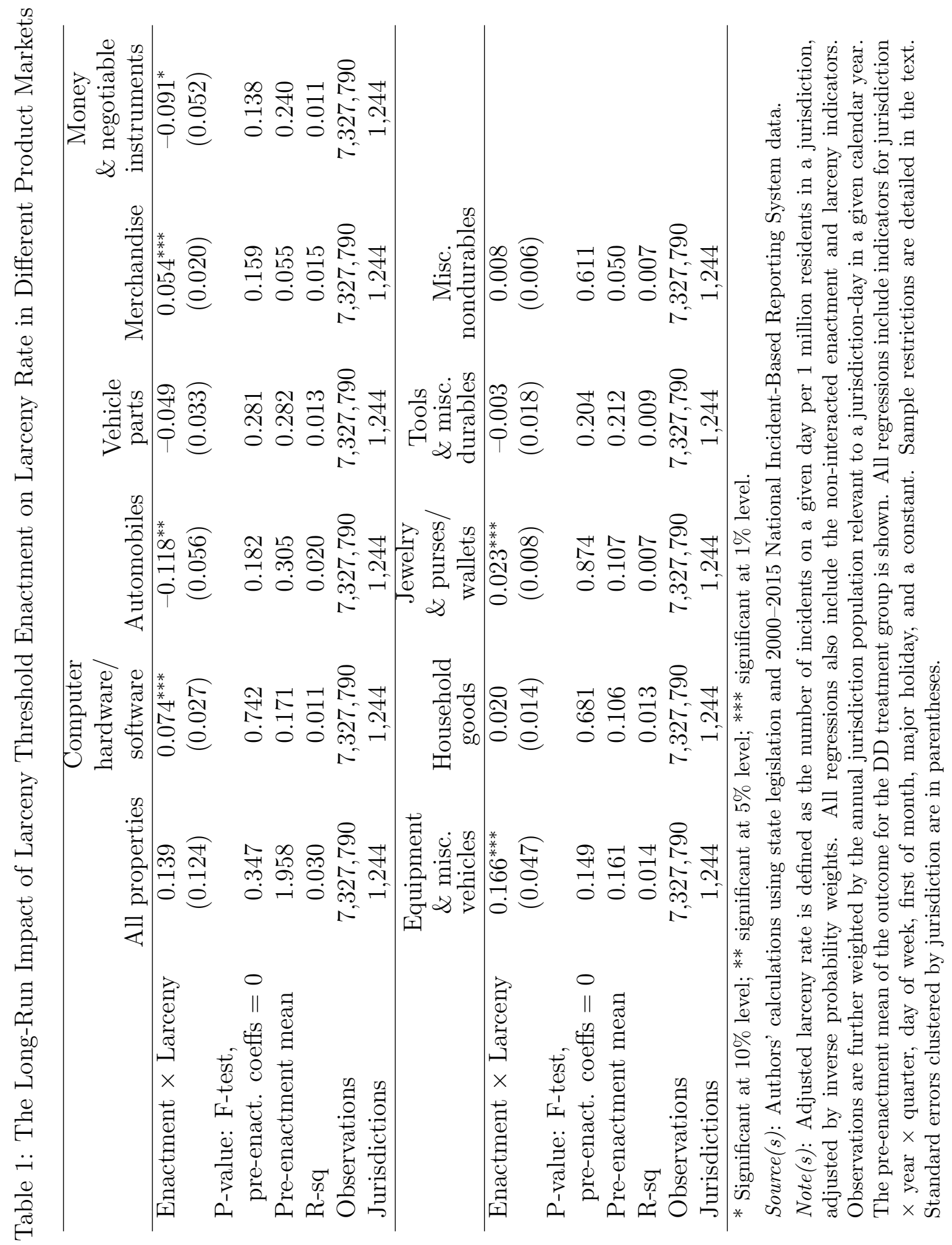




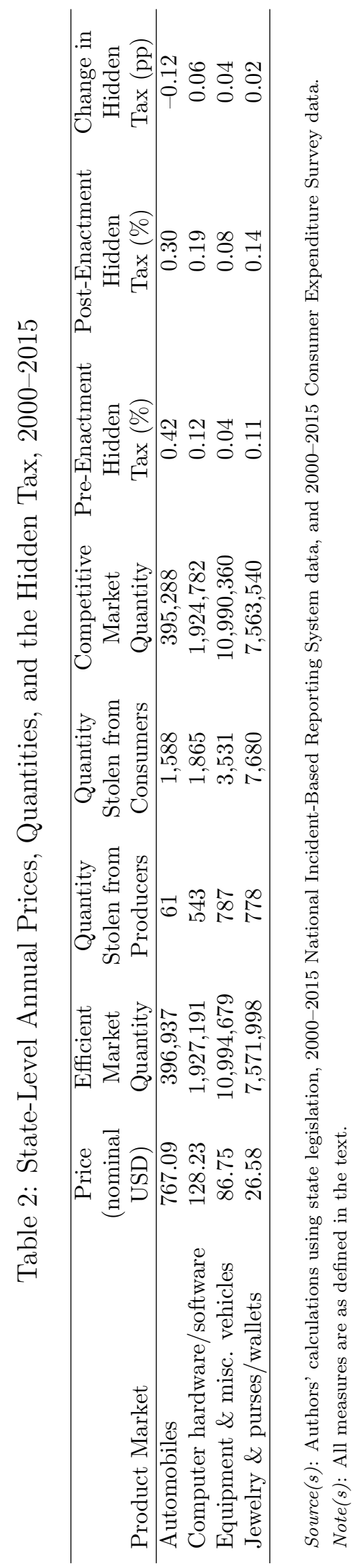


Table 3: Changes in State-Level Annual Welfare from the Hidden Tax, 2000-2015

\begin{tabular}{lcccc}
\hline & $\begin{array}{c}\text { Demand } \\
\text { Elasticity }\end{array}$ & $\begin{array}{c}\text { Change in } \\
\text { Competitive } \\
\text { Market Quantity }\end{array}$ & $\begin{array}{c}\text { Change in } \\
\text { Welfare } \\
\text { (nominal USD) }\end{array}$ & $\begin{array}{c}\text { Change in } \\
\text { Welfare, } \\
\text { Quantity }\end{array}$ \\
\hline Automobiles & -3.61 & 1,704 & $4,650.61$ & 6.06 \\
Computer hardware/software & -6.30 & $-7,450$ & $-1,487.26$ & -11.60 \\
Equipment \& misc. vehicles & -0.80 & $-3,222$ & -160.95 & -1.86 \\
Jewelry \& purses/wallets & -0.59 & $-1,064$ & -34.95 & -1.31 \\
\hline
\end{tabular}

Source(s): Authors' calculations using state legislation, 2000-2015 National Incident-Based Reporting System data, and 2000-2015 Consumer Expenditure Survey data.

Note $(s)$ : All measures are as defined in the text. Demand elasticities are obtained from the following studies, chosen to align with the assumptions of our conceptual framework as much as possible: (1) Berry, Levinsohn, and Pakes (1995) (-6.358) and McCarthy (1996) (-0.87), averaged; (2) Stavins (1997); (3) United States Department of Agriculture (2005); and (4) Batchelor and Gulle (1995). 


\section{A Appendix}

Table A1: Felony Larceny Threshold Changes in Sample, 2000-2015

\begin{tabular}{lcccc}
\hline State & $\begin{array}{c}\text { Enactment } \\
\text { Date }\end{array}$ & Bill/Act & $\begin{array}{c}\text { New } \\
\text { Threshold }\end{array}$ & $\begin{array}{c}\text { Prior } \\
\text { Threshold }\end{array}$ \\
\hline Arizona & $09 / 21 / 2006$ & HB2581 & $\$ 1,000$ & $\$ 250$ \\
Colorado & $07 / 01 / 2007$ & SB260 & $\$ 1,000$ & $\$ 500$ \\
Connecticut & $10 / 01 / 2009$ & HB6576 & $\$ 2,000$ & $\$ 1,000$ \\
Illinois & $01 / 01 / 2011$ & HB3797 & $\$ 500$ & $\$ 300$ \\
Kansas & $07 / 01 / 2004$ & HB2271 & $\$ 1,000$ & $\$ 500$ \\
Kentucky & $06 / 25 / 2009$ & HB369 & $\$ 500$ & $\$ 300$ \\
Louisiana & $08 / 15 / 2010$ & HB555 & $\$ 500$ & $\$ 300$ \\
Nebraska & $08 / 30 / 2015$ & LB605 & $\$ 1,500$ & $\$ 500$ \\
New Hampshire & $07 / 01 / 2010$ & SB205 & $\$ 1,000$ & $\$ 500$ \\
Ohio & $09 / 30 / 2011$ & HB86 & $\$ 1,000$ & $\$ 500$ \\
Oregon & $01 / 01 / 2010$ & HB2323 & $\$ 1,000$ & $\$ 750$ \\
Rhode Island & $06 / 08 / 2012$ & H7176 & $\$ 1,500$ & $\$ 500$ \\
South Carolina & $06 / 02 / 2010$ & SB1154 & $\$ 2,000$ & $\$ 1,000$ \\
Texas & $09 / 01 / 2015$ & HB1396 & $\$ 2,500$ & $\$ 1,500$ \\
Utah & $11 / 01 / 2010$ & SB10 & $\$ 1,500$ & $\$ 1,000$ \\
Vermont & $07 / 01 / 2006$ & SB265 & $\$ 900$ & $\$ 500$ \\
Washington & $09 / 01 / 2009$ & SB6167 & $\$ 750$ & $\$ 250$ \\
\hline
\end{tabular}

Source(s): State legislation.

Note(s): Inquiries sent to multiple officials in each state to confirm information (response rate: 4 out of 17 states). 
Table A2: Product Prices, 2000-2015

\begin{tabular}{|c|c|c|c|c|}
\hline File & $\begin{array}{l}\text { Product } \\
\text { Category }\end{array}$ & $\begin{array}{c}\text { Product } \\
\text { Description }\end{array}$ & $\begin{array}{l}\text { Product } \\
\text { Code }\end{array}$ & $\begin{array}{c}\text { Price } \\
\text { (nominal } \\
\text { USD) }\end{array}$ \\
\hline APA & Major appliances & Electric Stove or Oven & 100 & 450 \\
\hline APA & Major appliances & Microwave Oven & 120 & 84 \\
\hline APA & Major appliances & Portable Dishwasher & 170 & 318 \\
\hline APA & Major appliances & Clothes Washer & 190 & 400 \\
\hline APA & Major appliances & Clothes Dryer & 200 & 350 \\
\hline $\mathrm{APB}$ & Minor appliances & Small Electrical Kitchen Appliance & 230 & 30 \\
\hline $\mathrm{APB}$ & Minor appliances & Electric Personal Care Appliances & 240 & 25 \\
\hline $\mathrm{APB}$ & Minor appliances & Smoke Detectors & 250 & 27 \\
\hline $\mathrm{APB}$ & Minor appliances & Electric Floor Cleaning Equip. & 260 & 94 \\
\hline $\mathrm{APB}$ & Minor appliances & Other Household Appliances & 270 & 45 \\
\hline $\mathrm{APB}$ & Minor appliances & Sewing Machines & 280 & 115 \\
\hline $\mathrm{APB}$ & Minor appliances & Photographic Equipment & 300 & 139 \\
\hline $\mathrm{APB}$ & Minor appliances & Lawnmowing Machinery and Other Yard Equipment & 310 & 100 \\
\hline $\mathrm{APB}$ & Minor appliances & Power Tools & 320 & 95 \\
\hline $\mathrm{APB}$ & Minor appliances & Non-powered Tools & 330 & 30 \\
\hline $\mathrm{APB}$ & Minor appliances & Window Air Conditioners & 340 & 184 \\
\hline $\mathrm{APB}$ & Minor appliances & Portable Cooling and Heating Equipment & 350 & 40 \\
\hline $\mathrm{APB}$ & Minor appliances & Color televisions, portable and table models & 360 & 190 \\
\hline $\mathrm{APB}$ & Minor appliances & VCR, Video Camera, Video Disc Player, Camcorder & 390 & 96 \\
\hline $\mathrm{APB}$ & Minor appliances & Radio, all types & 400 & 40 \\
\hline $\mathrm{APB}$ & Minor appliances & Tape recorders and players & 420 & 43 \\
\hline $\mathrm{APB}$ & Minor appliances & Sound components, component systems and compact disc sound systems & 430 & 110 \\
\hline $\mathrm{APB}$ & Minor appliances & Other sound and video equipment, including accessories & 440 & 50 \\
\hline $\mathrm{APB}$ & Minor appliances & Other Musical Instruments and Musical Accessories & 460 & 49 \\
\hline $\mathrm{APB}$ & Minor appliances & Health and Exercise Equipment & 480 & 80 \\
\hline $\mathrm{APB}$ & Minor appliances & Camping Equipment & 490 & 53 \\
\hline $\mathrm{APB}$ & Minor appliances & Hunting and Fishing Equipment & 500 & 60 \\
\hline $\mathrm{APB}$ & Minor appliances & Winter Sports Equipment & 510 & 85 \\
\hline $\mathrm{APB}$ & Minor appliances & Water Sports Equipment & 520 & 45 \\
\hline $\mathrm{APB}$ & Minor appliances & Outboard Motors & 530 & 222 \\
\hline $\mathrm{APB}$ & Minor appliances & Bicycles & 540 & 85 \\
\hline $\mathrm{APB}$ & Minor appliances & Tricycles and Battery Powered Riders & 550 & 64 \\
\hline $\mathrm{APB}$ & Minor appliances & Playground Equipment & 560 & 75 \\
\hline $\mathrm{APB}$ & Minor appliances & Other Sports, Recreation and Exercise Equipment & 570 & 54 \\
\hline $\mathrm{APB}$ & Minor appliances & Telephone answering devices & 610 & 38 \\
\hline $\mathrm{APB}$ & Minor appliances & Computers, Computer systems and related hardware for non-business use & 640 & 194 \\
\hline $\mathrm{APB}$ & Minor appliances & Computer software and accessories for non-business use & 650 & 50 \\
\hline $\mathrm{APB}$ & Minor appliances & Telephones and accessories & 660 & 56 \\
\hline $\mathrm{APB}$ & Minor appliances & Satellite dishes & 670 & 100 \\
\hline CLA & Clothing (A) & Coats, jackets, furs & 100 & 53 \\
\hline CLA & Clothing (A) & Sport coats and tailored jackets & 110 & 67 \\
\hline CLA & Clothing (A) & Suits & 120 & 128 \\
\hline CLA & Clothing (A) & Sweaters and sweater sets & 140 & 40 \\
\hline CLA & Clothing (A) & Pants, slacks, \& jeans & 150 & 48 \\
\hline CLA & Clothing (A) & Dresses & 170 & 60 \\
\hline CLA & Clothing (A) & Skirts & 180 & 32 \\
\hline CLA & Clothing (A) & Shirts, blouses and tops & 190 & 39 \\
\hline CLA & Clothing (A) & Undergarments & 200 & 20 \\
\hline CLA & Clothing (A) & Hosiery & 210 & 11 \\
\hline CLA & Clothing (A) & Nightwear and loungewear & 220 & 22 \\
\hline CLA & Clothing (A) & Accessories & 230 & 20 \\
\hline CLA & Clothing (A) & Active sportswear & 240 & 32 \\
\hline CLA & Clothing (A) & Uniforms (for which not reimbursed) & 250 & 60 \\
\hline CLA & Clothing (A) & Costumes & 260 & 32 \\
\hline CLA & Clothing (A) & Footwear (include athletic shoes not specifically purchased for sports-related use) & 280 & 45 \\
\hline CLB & Clothing (B) & Bedroom Linens & 200 & 18 \\
\hline CLB & Clothing (B) & Bathroom Linens & 201 & 10 \\
\hline CLB & Clothing (B) & Infants coats, jackets or snowsuits & 290 & 21 \\
\hline CLB & Clothing (B) & Infants dresses and outerwear & 300 & 32 \\
\hline CLB & Clothing (B) & Infants underwear and diapers, including disposable & 310 & 40 \\
\hline CLB & Clothing (B) & Infants sleeping garment & 320 & 18 \\
\hline CLB & Clothing (B) & Infants accessories & 340 & 16 \\
\hline
\end{tabular}






Source(s): Authors' calculations using 2000-2015 Consumer Expenditure Survey data.

Note(s): We impose the following sample restrictions when calculating the typical (median) product prices in the table, as described in the text: (1) cross-sectional (17 states only [see Appendix Table A1], excluding households with roughly zero food consumption, excluding households with multiple state locations over time); (2) temporal (excluding periods with census-related sample adjustments [2005:Q1 and 2015:Q1], focusing on state-specific pre-enactment periods); and (3) price (state-specific maximum prices at the new felony larceny threshold minus $\$ 1$ ). Underlying observations to generate prices are weighted by household. 


\section{Table A3: Categorization of Stolen Properties in NIBRS Data}

\begin{tabular}{|c|c|}
\hline Property Category & NIBRS Stolen Property Description \\
\hline Computer hardware/software & Computer hardware/software \\
\hline Various electronics & Radios/tvs/vcrs/dvd players \\
\hline Various electronics & Recordings-audio/visual \\
\hline Various electronics & Portable electronic communications \\
\hline Automobiles & Automobiles \\
\hline Automobiles & Trucks \\
\hline Vehicle parts & Vehicle parts/accessories \\
\hline Merchandise & Merchandise \\
\hline Money \& negotiable instruments & Money \\
\hline Money \& negotiable instruments & Negotiable instruments \\
\hline Bicycles & Bicycles \\
\hline Equipment \& misc. vehicles & Aircraft \\
\hline Equipment \& misc. vehicles & Buses \\
\hline Equipment \& misc. vehicles & Drug/narcotic equip. \\
\hline Equipment \& misc. vehicles & Farm equipment \\
\hline Equipment \& misc. vehicles & Gambling equipment \\
\hline Equipment \& misc. vehicles & Heavy construction/industrial equipment \\
\hline Equipment \& misc. vehicles & Office-type equipment \\
\hline Equipment \& misc. vehicles & Other motor vehicles \\
\hline Equipment \& misc. vehicles & Recreational vehicles \\
\hline Equipment \& misc. vehicles & Watercraft \\
\hline Equipment \& misc. vehicles & Aircraft parts/accessories \\
\hline Equipment \& misc. vehicles & Camping/hunting/fishing equipment/supplies \\
\hline Equipment \& misc. vehicles & Law enforcement equipment \\
\hline Equipment \& misc. vehicles & Lawn/yard/garden equipment \\
\hline Equipment \& misc. vehicles & Logging equipment \\
\hline Equipment \& misc. vehicles & Medical/medical lab equipment \\
\hline Equipment \& misc. vehicles & Photographic/optical equipment \\
\hline Equipment \& misc. vehicles & Recreational/sports equipment \\
\hline Equipment \& misc. vehicles & Trailers \\
\hline Equipment \& misc. vehicles & Watercraft equipment/parts/accessories \\
\hline Weapons \& related accessories & Firearms \\
\hline Weapons \& related accessories & Explosives \\
\hline Weapons \& related accessories & Firearm accessories \\
\hline Weapons \& related accessories & Weapons-other \\
\hline Household goods & Household goods \\
\hline Jewelry \& purses/wallets & Jewelry/precious metals/gems \\
\hline Jewelry \& purses/wallets & Purses/handbags/wallets \\
\hline Tools \& misc. durables & Livestock \\
\hline Tools \& misc. durables & Structures-single occupancy dwellings \\
\hline Tools \& misc. durables & Structures-other dwellings \\
\hline Tools \& misc. durables & Structures-commercial/business \\
\hline Tools \& misc. durables & Structures-industrial/manufacturing \\
\hline Tools \& misc. durables & Structures-public/community \\
\hline Tools \& misc. durables & Structures-storage \\
\hline Tools \& misc. durables & Structures-other \\
\hline Tools \& misc. durables & Tools-power/hand \\
\hline Tools \& misc. durables & Artistic supplies/accessories \\
\hline Tools \& misc. durables & Building materials \\
\hline Tools \& misc. durables & Collections/collectibles \\
\hline Tools \& misc. durables & Metals, non-precious \\
\hline Tools \& misc. durables & Musical instruments \\
\hline Tools \& misc. durables & Pets \\
\hline Misc. nondurables & Alcohol \\
\hline Misc. nondurables & Clothes/furs \\
\hline Misc. nondurables & Consumable goods \\
\hline Misc. nondurables & Drugs/narcotics \\
\hline Misc. nondurables & Chemicals \\
\hline Misc. nondurables & Crops \\
\hline Misc. nondurables & Fuel \\
\hline
\end{tabular}

Source(s): 2000-2015 National Incident-Based Reporting System data. 